\title{
Article
}

\section{An Experimental Investigation of the Adsorption of a Phosphonic Acid on the Anatase Ti02(101) Surface}

Wagstaffe, Michael, Thomas, Andrew G., Jackman, Mark. J., TorresMolina, Maria, Syres, Karen and Handrup, Karsten

Available at https://clok.uclan.ac.uk/13977/

Wagstaffe, Michael, Thomas, Andrew G., Jackman, Mark. J., Torres-Molina, Maria, Syres, Karen orcid iconORCID: 0000-0001-7439-475X and Handrup, Karsten (2016) An Experimental Investigation of the Adsorption of a

Phosphonic Acid on the Anatase TiO2(101) Surface. The Journal of Physical Chemistry C, 120 (3). pp. 1693-1700. ISSN 1932-7447

It is advisable to refer to the publisher's version if you intend to cite from the work. http://dx.doi.org/10.1021/acs.jpcc.5b11258

For more information about UCLan's research in this area go to

http://www.uclan.ac.uk/researchgroups/ and search for <name of research Group>.

For information about Research generally at UCLan please go to http://www.uclan.ac.uk/research/

All outputs in CLoK are protected by Intellectual Property Rights law, including Copyright law. Copyright, IPR and Moral Rights for the works on this site are retained by the individual authors and/or other copyright owners. Terms and conditions for use of this material are defined in the policies page. 


\title{
An Experimental Investigation of the Adsorption of a Phosphonic Acid on the Anatase $\mathrm{TiO}_{2}(101)$ Surface
}

\author{
Michael Wagstaffe,,$^{\dagger}$ Andrew G. Thomas, ${ }^{*}{ }^{\ddagger}$ Mark. J. Jackman, ${ }^{\dagger}$ Maria Torres-Molina, ${ }^{\S}$ Karen L. Syres, ${ }^{\prime \prime}$ \\ and Karsten Handrup ${ }^{\perp}$ \\ ${ }^{\dagger}$ School of Physics and Astronomy, ${ }^{\ddagger}$ School of Materials and Photon Science Institute, and ${ }^{\S}$ School of Chemistry, The University of \\ Manchester, Oxford Road, Manchester M13 9PL, U.K. \\ "Jeremiah Horrocks Institute, The University of Central Lancashire, Fylde Road, Preston PR1 2HE, U.K. \\ ${ }^{\perp}$ MaxLab, Ole Römers Väg, Lund, Sweden
}

\section{Supporting Information}

ABSTRACT: A combination of synchrotron radiation photoelectron spectroscopy and near-edge X-ray absorption fine structure (NEXAFS) spectroscopy has been used to study the adsorption of phenylphosphonic acid (PPA) on anatase $\mathrm{TiO}_{2}(101)$ single crystal at coverages of 0.15 monolayer $(\mathrm{ML})$ and $0.85 \mathrm{ML}$. The photoelectron spectroscopy data suggest that at $0.15 \mathrm{ML}$ coverage PPA adsorbs in a bidentate geometry following deprotonation of both phosphonate hydroxyl groups, leaving the $\mathrm{P}=\mathrm{O}$ group unbound. At $0.85 \mathrm{ML}$ there is a shift to a mixed bidentate/ monodentate binding mode. The carbon K-edge NEXAFS spectra were recorded at two azimuths. Our calculations show that for PPA on anatase

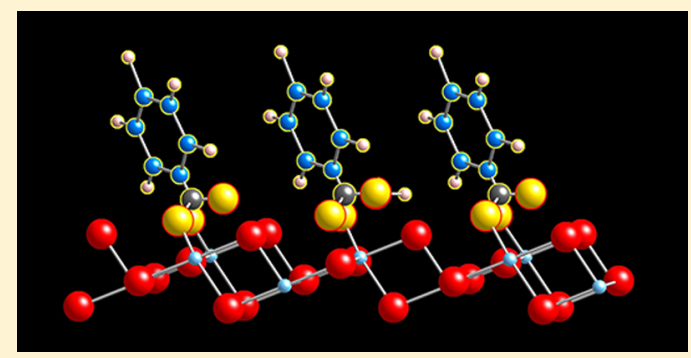
$\mathrm{TiO}_{2}(101)$ the phenyl ring is oriented $65 \pm 4^{\circ}$ away from the surface plane with an azimuthal twist of $57 \pm 11^{\circ}$ away from the $[10 \overline{1}]$ azimuth.

\section{INTRODUCTION}

$\mathrm{TiO}_{2}$ has applications in a wide range of fields, including photovoltaics $^{1-5}$ and catalysis. ${ }^{6,7}$ In addition, it is also thought to contribute to the high biocompatibility of $\mathrm{Ti}$ used in biomedical implants. ${ }^{8-10}$ It is extremely abundant, has cheap manufacturing costs, and is both nontoxic and highly resistant to corrosion. ${ }^{11}$ In solar applications the wide band gap of $\mathrm{TiO}_{2}$ means that it is unable to efficiently utilize solar radiation, and as a result the surface functionalization and doping of $\mathrm{TiO}_{2}$ have become highly researched areas. The adsorption of various organic dyes, particularly those containing aromatic ligands, on $\mathrm{TiO}_{2}$ have been investigated in an attempt to shift the adsorption onset. ${ }^{12-16}$ Functional groups on the dye molecule anchor the dye to the surface of a substrate and direct the charge transfer between the light harvesting molecule and the conduction band of the semiconductor. ${ }^{13}$ As well as dyes, quantum dots have been suggested as light harvesting entities. In these quantum-dot-sensitized systems, in order to facilitate charge transfer between the excited quantum dot and the ntype material, linker molecules capable of bonding to both the n-type material and quantum dot are required. ${ }^{17}$ One may expect that aromatic molecules may promote fast electron transfer due to the resonance structures offered by aromatics which can stabilize electrons or holes in the molecules. ${ }^{18}$

Some of the most efficient dye-sensitized solar cells (DSSCs) utilize dyes containing the carboxylic acid functional group. Despite the excellent electronic coupling between the dye and the semiconductor that this group provides, long-term stability has been seen to be an issue. ${ }^{19,20}$ This has led to investigations into alternate functional groups that can be used to anchor dyes to the semiconductor surface, one of the most promising being phosphonic acid, shown in phenylphosphonic acid in Figure $1 .^{21-31}$ Studies indicate that this binds more strongly to metal<smiles>O=P(O)(O)c1ccccc1</smiles>

Figure 1. Molecular structure of phenylphosphonic acid. The numbering of the $\mathrm{C}$ atoms is used in assignment of the photoemission features discussed in the Results section.

oxide surfaces and as a result will have improved long-term stability. $^{24}$ Experimentally, the interaction between the phosphonic acid functional group and $\mathrm{TiO}_{2}$ is difficult to assess, and thus experiments often lead to conflicting/indefinite conclusions. ${ }^{32}$ Various techniques have been utilized in an attempt to determine the bonding mechanism, including high field ${ }^{17} \mathrm{O}$ MAS NMR (magic angle spinning nuclear magnetic resonance) $)^{30}$ and FTIR (Fourier transform infrared) spectroscopy. ${ }^{26}$ While it is generally accepted that the phosphonic acid functional group binds to the $\mathrm{TiO}_{2}$ surface via $\mathrm{Ti}-\mathrm{O}-\mathrm{P}$ bonds,

Received: November 17, 2015

Revised: January 2, 2016

Published: January 5, 2016 
a variety of different bonding mechanisms have been postulated, including monodentate, bidentate, and tridentate. Luschtinetz et al. ${ }^{32}$ conducted an extensive investigation into the various adsorption complexes of phosphonic acid on the anatase $\mathrm{TiO}_{2}(101)$ surface using quantum chemical periodic hybrid $a b$ initio Hartree-Fock density functional theory calculations. Their work suggested that the most stable adsorption configuration on the anatase $\mathrm{TiO}_{2}(101)$ surface is that of a bidentate structure. In their optimized structure, which has an adsorption energy of $277 \mathrm{~kJ} / \mathrm{mol}$, the adsorbed phosphonic acid is fully dissociated and the $\mathrm{P}=\mathrm{O}$ bond is not involved in the surface bonding. Their work also showed that there were several alternative bidentate configurations which had similar adsorption energies but different geometries. This was reinforced by Francesco Ambrosio et al., ${ }^{33}$ who studied electron injection times for phosphonated dyes bonded in various configurations, adding that this configuration also generally led to faster injection times. While DFT studies completed by O'Rourke and Bowler ${ }^{34}$ agreed in the sense that the most stable adsorption mode for phosphonic acid is the bidentate bridging mode, it was a different bidentate configuration to that put forward by Luschtinetz et al., bonding through the phosphonyl and a single $\mathrm{OH}$ group. Additionally they noted a comparably stable monodentate configuration, where the phosphonic acid binds solely through its phosphonyl group. It is likely the close relative stabilities of these various adsorption modes that has stopped a general consensus being reached.

Here, in an attempt to clarify the interaction of a phosphonic acid with the titania surface, we use X-ray photoelectron spectroscopy (XPS) and near-edge X-ray absorption fine structure (NEXAFS) spectroscopy to study phenylphosphonic acid adsorption on single crystal anatase $\mathrm{TiO}_{2}(101)$. XPS and NEXAFS have been successfully employed to study the interaction of carboxylic acids with $\mathrm{TiO}_{2}$ surfaces. ${ }^{12,35}$ The anatase $\mathrm{TiO}_{2}(101)$ surface is chosen since it is likely to be the dominant surface exposed in nanoparticle $\mathrm{TiO}_{2}$, which is the form generally used in DSSCs based on $\mathrm{TiO}_{2}{ }^{12,14,32,36}$

\section{EXPERIMENTAL SECTION}

The work was carried out on the bending magnet soft X-ray beamline, D1011 (photon energy range $30 \mathrm{eV}<h \nu<1600 \mathrm{eV}$ ), at MAX-lab, Sweden. The analysis chamber is equipped with a SCIENTA SES200 hemispherical electron energy analyzer, for photoemission experiments, and a multichannel partial yield detector, for use in NEXAFS experiments.

The anatase $\mathrm{TiO}_{2}$ single crystal $(5 \mathrm{~mm} \times 5 \mathrm{~mm}$, Pikem Ltd.) was mounted on a Mo sample plate using tantalum wire and cleaned by repeated $1 \mathrm{keV} \mathrm{Ar}^{+}$ion bombardment and annealing up to temperatures of $700{ }^{\circ} \mathrm{C}$ until a sharp $1 \times 1$ LEED pattern, as shown in Figure 2, was obtained, and X-ray photoelectron spectra showed the surface to be free of contamination (see Supporting Information Figure S.1). All photoemission spectra are recorded at normal emission at room temperature. All binding energies $(\mathrm{BE})$ are referenced to a Fermi edge recorded from the sample plate (with an associated error of $\pm 0.1 \mathrm{eV}$ ).

NEXAFS spectra were recorded over the $\mathrm{C}$ K-edge with incident photon angles, $\theta$, as shown in Figure $2 \mathrm{~b}$, ranging between $20^{\circ}$ and $90^{\circ}$, in increments of $10^{\circ}$. Data were recorded with the surface component of the electric vector of the incident radiation at two orthogonal angles as marked in Figure $2 .^{37}$ The partial yield detector was tuned to retard electrons with a kinetic energy of less than $200 \mathrm{eV}$. The sample

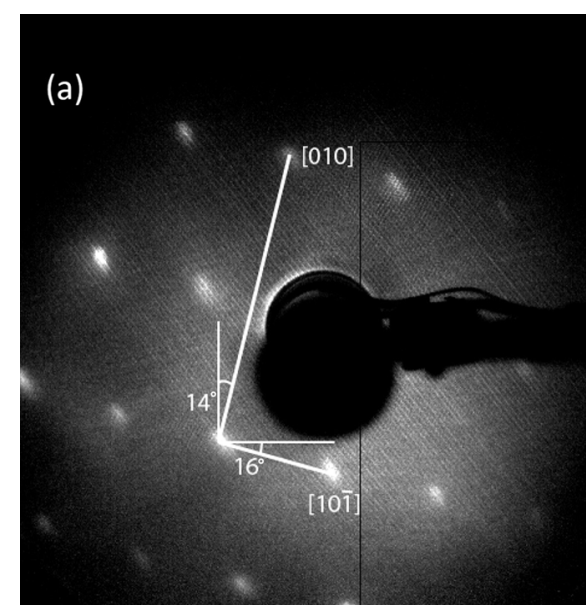

(b)

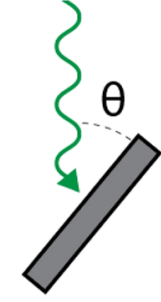

Figure 2. (a) $1 \times 1$ LEED pattern obtained for for anatase $\mathrm{TiO}_{2}(101)$ surface. The arrows show how the azimuthal angle is defined in the NEXAFS experiments described below. (b) Definition of the polar angle in the NEXAFS experiments.

manipulator on the end station does not allow in situ azimuthal rotation. In order to measure the second azimuth, the sample had to be removed from the vacuum system, remounted, and the surface reprepared and redosed, which may lead to slight differences in substrate signal between azimuths.

Phenylphosphonic acid (PPA) (99.95\%, Sigma-Aldrich) was deposited on the anatase surface via evaporation into the vacuum chamber. The PPA powder was inserted into a glass crucible, and the temperature was slowly increased to around $130{ }^{\circ} \mathrm{C}$ over a period of around an hour in order to remove any impurities and adsorbed gases. The crucible temperature was then reduced and held at around $80{ }^{\circ} \mathrm{C}$ when not in use. In order to "dose" the $\mathrm{TiO}_{2}$ crystal, the evaporator was heated to around $120^{\circ} \mathrm{C}$ at a pressure of $5 \times 10^{-8}$ mbar with the anatase crystal at room temperature and facing the evaporator.

To calculate NEXAFS spectra of the gas-phase PPA molecule, we used GaussView and Gaussian $03^{38}$ to produce energy-minimized geometry-optimized structures in order to obtain the atomic coordinates. These calculations were carried out using DFT B3LYP theory and the $6-31 G(d, p)$ basis set. The coordinates obtained from Gaussian were then used to carry out further DFT calculations using the StoBe-deMon code. $^{39}$ StoBe was used to calculate the excited-state X-ray absorption spectra for each $\mathrm{C}$ atom in the molecule individually. The summation of the individual energy-calibrated spectra gives the theoretical angle-integrated NEXAFS spectrum for the molecule.

\section{RESULTS AND DISCUSSION}

X-ray Photoelectron Spectroscopy. Core-level photoelectron spectra are shown in Figure 3 for $\mathrm{Ti} 2 \mathrm{p}, \mathrm{O} 1 \mathrm{~s}, \mathrm{C} 1 \mathrm{~s}$, and $\mathrm{P} 2 \mathrm{p}$. Fitting of core level spectra was carried out in CasaXPS, utilizing Gaussian:Lorentzian curves (0.7:0.3) atop a Shirley background.

The Ti $2 \mathrm{p}$ spectra prior to adsorption shows the main oxide peak due to $\mathrm{Ti}^{4+}$ at a binding energy of $458.7 \mathrm{eV}$, with a small shoulder at a lower binding energy of $457.1 \mathrm{eV}$, indicating the presence of around $4 \%$ of $\mathrm{Ti}^{3+}$ in the near surface region. ${ }^{36}$ Following adsorption of the phenylphosphonic acid no changes are observed in the Ti $2 \mathrm{p}$ spectrum. The $\mathrm{C} 1 \mathrm{~s}$ peak is composed of two components, at energies 284.8 and $286.1 \mathrm{eV}$. These peaks are assigned to electron emission from carbon atoms 

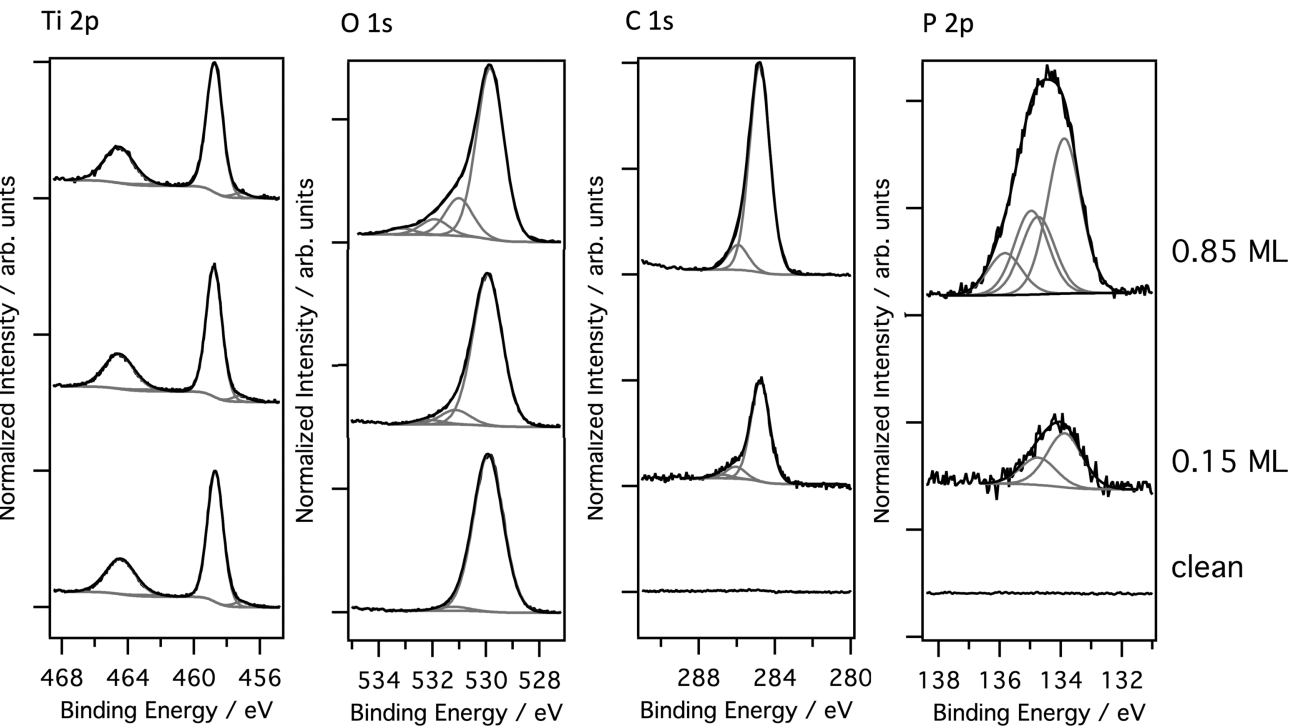

Figure 3. Ti 2p (photon energy $570 \mathrm{eV}$ ), O 1s (photon energy $650 \mathrm{eV}$ ), C 1s (photon energy $385 \mathrm{eV}$ ), and P 2p (photon energy $220 \mathrm{eV}$ ) XPS corelevel spectra showing, from bottom to top, the clean anatase $\mathrm{TiO}_{2}(101)$ surface, the anatase $\mathrm{TiO}_{2}(101)$ single crystal following the adsorption of ca. 0.15 monolayer $(\mathrm{ML})$ of PPA, and the anatase $\mathrm{TiO}_{2}(101)$ single crystal following the adsorption of ca. $0.85 \mathrm{ML}$ of PPA.

labeled $1-5$ and that labeled 6 (the chemically shifted $\mathrm{C}$ atom bonded to P) as shown in Figure 1. From Figure 1 one would expect the ratio of the two fitted peaks to have a ratio of $5: 1$. The experimentally observed ratio of 5:0.6, for both coverages shown here, is in relatively good agreement with the expected ratio. The slight discrepancy in the ratio could be due to a difference in attenuation length, or photoelectron diffraction effects, which may affect the relative intensity of emission from $\mathrm{C}$ atoms located closer to the surface. ${ }^{40}$ It is also possible that it is due to small amounts of carbon contamination. Although it was not performed in this experiment, angle-resolved XPS measurements could be used to determine whether this is a real experimental effect. In order to determine the coverage of the PPA for the two exposures we compared the ratio of the total C 1s signal and the $\mathrm{Ti} 2 \mathrm{p}_{3 / 2}$ signal following adsorption to that of catechol, which also contains a single phenyl ring, but is known to saturate at monolayer coverage. ${ }^{41-43}$ This gives us a nominal coverage of around 0.15 monolayer $(\mathrm{ML})$ for the lower exposure and 0.85 ML for the higher exposure. By analogy with carboxylic acid adsorption we assume that two $\mathrm{Ti} 5 \mathrm{c}$ atoms are involved in the bonding of a single molecule to the surface, and so a monolayer is defined as 3 molecules $/ \mathrm{nm}^{2}$ (see Supporting Information, section S.2, for the calculation). The binding energies and relative peak areas for all of the features observed in the XPS spectra are shown in Table 1.

The O 1s spectra shown in Figure 3 are all dominated by the substrate oxide peak at a binding energy of $529.9 \mathrm{eV} .^{36,44,45}$ The binding energy of the oxide related $\mathrm{O} 1 \mathrm{~s}$ peak does not change following adsorption of the PPA molecule. A small peak at binding energy $531.1 \mathrm{eV}$ is also required in the fitting. The precise nature of this peak is the subject of some debate, it may arise from hydroxyls adsorbed from the residual vacuum, but it has also been suggested that it is intrinsic to the $\mathrm{O} 1 \mathrm{~s}$ peak of the anatase $\mathrm{TiO}_{2}(101)$ surface. ${ }^{36}$ It can be seen that following exposure of the anatase $\mathrm{TiO}_{2}(101)$ surface to PPA additional O-related features appear at the high binding energy side of the oxides $\mathrm{O}$ 1s peak, at similar energies to those seen following carboxylic acid ${ }^{12}$ and catechol ${ }^{41}$ adsorption on this surface.
Table 1. Peak Assignments, Their Respective Binding Energies, and the Relative Abundances as a Percentage of Total Peak Area That Are Fitted to the Core Spectra of PPA Adsorbed on Anatase for 0.15 and 0.85 ML Coverages ${ }^{a}$

\begin{tabular}{|c|c|c|c|c|c|}
\hline \multirow[b]{2}{*}{ species } & \multirow[b]{2}{*}{ assignment } & \multicolumn{2}{|c|}{$0.15 \mathrm{ML}$} & \multicolumn{2}{|c|}{$0.85 \mathrm{ML}$} \\
\hline & & $\mathrm{BE}(\mathrm{eV})$ & $\%$ & $\mathrm{BE}(\mathrm{eV})$ & $\%$ \\
\hline \multirow[t]{2}{*}{ Ti $2 p_{3 / 2}$} & $\mathrm{Ti}^{3+}$ & 457.2 & 4.5 & 457.1 & 3.7 \\
\hline & $\mathrm{Ti}^{4+}$ & 458.8 & 95.5 & 458.7 & 96.3 \\
\hline \multirow[t]{4}{*}{$\mathrm{O} 1 \mathrm{~s}$} & $\mathrm{TiO}_{2}$ & 529.9 & 88.9 & 529.9 & 74.2 \\
\hline & $\mathrm{TiOH} / \mathrm{P}-\mathrm{O}^{-}$ & 531.1 & 8.5 & 531.1 & 16.3 \\
\hline & $\mathrm{P}=\mathrm{O}$ & 532.1 & 2.6 & 532.0 & 6.8 \\
\hline & $\mathrm{P}-\mathrm{OH}$ & & 0 & 533.3 & 2.7 \\
\hline \multirow[t]{2}{*}{ C $1 \mathrm{~s}$} & $C(1-5)$ & 284.8 & 89.4 & 284.8 & 89.3 \\
\hline & C (6) & 286.1 & 10.6 & 286.0 & 10.7 \\
\hline \multirow[t]{2}{*}{$\mathrm{P} 2 \mathrm{p}_{3 / 2}$} & $\mathrm{PO}_{3}^{2-}$ & 133.9 & 100 & 133.9 & 64.9 \\
\hline & $\mathrm{PO}_{2}(\mathrm{OH})^{-}$ & & 0 & 135 & 35.1 \\
\hline
\end{tabular}

Figure 4 shows a magnified view of the region in the $\mathrm{O} 1 \mathrm{~s}$ spectra where the adsorbate related features lie. For the surface following adsorption of ca. $15 \%$ of a monolayer two peaks are fitted at binding energies of $531.1 \mathrm{eV}$, peak c, and $532.1 \mathrm{eV}$, peak $b$. These peaks are both assigned to $O$ in the adsorbed PPA complex. Previous work on the pure PPA molecule in powder form, i.e., the intact acid, has shown the $\mathrm{O}$ 1s to be made up of two components arising from $\mathrm{P}=\mathrm{O}$ and $\mathrm{P}-\mathrm{OH}$ with a peak separation of $1.4 \mathrm{eV}, 4,46$ which is substantially larger than that seen here. From this it can be inferred that the molecule is bonding to the anatase $\mathrm{TiO}_{2}(101)$ surface via the phosphonic acid group, since if there was no interaction between the phosphonate group and the anatase $\mathrm{TiO}_{2}(101)$ surface, one would expect the $\mathrm{O} 1 \mathrm{~s}$ spectrum to resemble that of the molecule in the powder state. Furthermore, the presence of two additional features in the $\mathrm{O} 1 \mathrm{~s}$ spectrum following adsorption suggests the $\mathrm{O}$ atoms in the phosphonate group are not in equivalent chemical states; i.e., bonding does not occur through all three of the phosphonate $\mathrm{O}$ atoms. The binding energy of the peak fitted with the red line, peak $b$, is consistent 


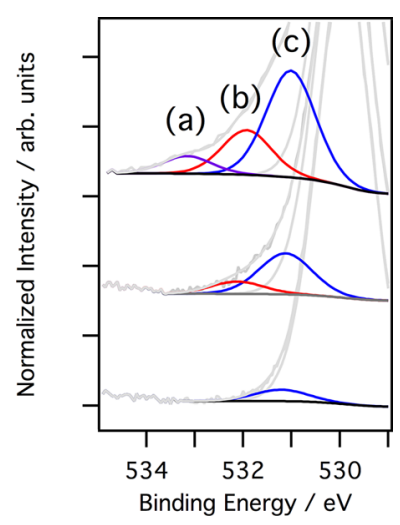

Figure 4. O 1s spectra, focusing on the peaks introduced after dosing PPA to the high binding energy side of the oxide peak. The blue curve (c) is assigned to $\mathrm{Ti}-\mathrm{O}-\mathrm{P}$ bonds following dissociation of the $\mathrm{OH}$ groups and the red curve $(\mathrm{b})$ to the unbound phosphonyl $\mathrm{P}=\mathrm{O}$. At the $0.85 \mathrm{ML}$ coverage a third peak is evident, marked by a purple line (a), which arises from undissociated $\mathrm{P}-\mathrm{OH}$.

with the binding energy of $\mathrm{O} 1 \mathrm{~s}$ in $\mathrm{P}=\mathrm{O}$. The binding energy of peak $\mathrm{c}$ at $531.1 \mathrm{eV}$, however, is much lower than would be expected for that for the intact $\mathrm{P}-\mathrm{OH}$ group, ${ }^{44,46,47}$ suggesting that the $\mathrm{OH}$ groups are deprotonated. Thus, we propose that the molecule bonds to surface $\mathrm{Ti}$ atoms via the two deprotonated $\mathrm{OH}$ groups with the $\mathrm{P}=\mathrm{O}$ not directly bonded to the surface.

Looking at the ratio of the areas of the two peaks, we obtain a value of 2:0.6 for $\mathrm{P}-\mathrm{O}-\mathrm{Ti}: \mathrm{P}=\mathrm{O}$, which is in relatively good agreement with the expected value of $2: 1$, particularly when one considers that, as mentioned above, there is some intrinsic component of the oxide $\mathrm{O} 1 \mathrm{~s}$ in the region of the $\mathrm{P}-\mathrm{O}-\mathrm{Ti}$ related feature. Theoretical studies of PPA adsorption on this surface generally find the bidentate mode to be the lowest energy mode. This is because of the distance between the neighboring rows of surface $\mathrm{Ti}$ atoms, which would introduce strain into the molecular adsorbate in order to obtain the tridentate mode. ${ }^{32}$ Theory suggests the unbound phosphonyl group actually interacts with surface hydroxyls formed during adsorption of the acid via H-bonding. ${ }^{48}$ The uppermost curve in Figure 4 shows the appearance of a third feature, peak a, in the $\mathrm{O} 1 \mathrm{~s}$ spectrum at a binding energy of $533.3 \mathrm{eV}$, as the PPA coverage is increased to $85 \%$ of a ML. The binding energy of this peak corresponds to that of $\mathrm{P}-\mathrm{OH}$ in the unbound molecule. ${ }^{47}$ An increase in the intensity of the peaks assigned to $\mathrm{P}=\mathrm{O}$ and $\mathrm{P}-\mathrm{O}-\mathrm{Ti}$ is also observed. There are two possible explanations for the appearance of this third peak. First, at this higher exposure a second layer has begun to form on top of the first layer. This results in a first layer consisting of $\mathrm{P}-\mathrm{O}-\mathrm{Ti}$ and $\mathrm{P}=\mathrm{O}$ with the intact acid in the second layer. It is also plausible that as the coverage increases there is a change in bonding mode, where the reduced availability of surface $\mathrm{Ti}$ atoms as the coverage increases results in some molecules adsorbing in a monodentate fashion.

The P 2p spectra help us determine the most likely reason for the observed change in the $\mathrm{O}$ 1s spectra at higher coverage. For the $0.15 \mathrm{ML}$ coverage, two peaks are fitted at 133.9 and $134.8 \mathrm{eV}$, which account for the spin-orbit splitting of the P $2 \mathrm{p}$ level, with the expected separation of $0.9 \mathrm{eV}^{49}$ and the intensity relationship. At $0.85 \mathrm{ML}$ coverage, a second $\mathrm{P} 2 \mathrm{p}$ doublet is required to fit the data with $\mathrm{P} 2 \mathrm{p}_{3 / 2}$ and $2 \mathrm{p}_{1 / 2}$ split peaks at binding energies of 135.0 and $135.9 \mathrm{eV}$, respectively. This suggests two chemical states of $\mathrm{P}$ at the higher coverage, consistent with the change in the $\mathrm{O} 1 \mathrm{~s}$ spectrum at higher coverage. The ratio between the areas of the $\mathrm{P} 2 \mathrm{p}_{3 / 2}$ peaks (low $\mathrm{BE}$ :higher $\mathrm{BE}$ ) is $2: 1$, suggesting the bidentate adsorption mode observed in the $0.15 \mathrm{ML}$ coverage is still dominant at higher coverage. From this we can make an assumption about the binding mode of the minority species by looking at the peak areas of the O 1s peaks labeled (a) and (c) in Figure 4. Since we can see from the P $2 p$ spectra that the ratio of bidentate to the unknown binding mode is $2: 1$, we can infer that for multilayer formation we would also expect the ratio of the two O 1s peaks to be roughly 2:1 (c:a). This is because for every two bidentate adsorbed molecules we would have four $\mathrm{P}-\mathrm{O}-$ $\mathrm{Ti}$ end groups (peak c in Figure 4) and one unbonded molecule with two $\mathrm{P}-\mathrm{OH}$ groups (peak a in Figure 4). Alternatively, we can consider a mixed bidentate-monodentate mode, with two bidentate adsorbed molecules (four $\mathrm{P}-\mathrm{O}-\mathrm{Ti}$ groups) and one monodentate (one $\mathrm{P}-\mathrm{O}-\mathrm{Ti}$ and one $\mathrm{P}-\mathrm{OH}$ group); this would give a peak area ratio of 5:1 (c:a).

These calculations assume that the dissociated $\mathrm{H}$ atoms do not go on to produce adsorbed surface hydroxyls. As mentioned above, the oxygen 1s signal for adsorbed surface hydroxyls lies at the same energy as peak c. If we assume every dissociated $\mathrm{H}$ atom leads to an adsorbed surface hydroxyl, one would expect the ratio of c:a to be $10: 1$ for the mixed bidentate-monodentate system or $4: 1$ for multilayer formation. The measured ratio of $6: 1$ lies in the range associated with the mixed bidentate-monodentate adsorption mode. It seems that as the coverage increases there is a shift toward a mixed adsorption mode. This is further supported by the fact the carbon spectra suggests we have submonolayer coverage $(0.85$ $\mathrm{ML}$ ) and the observed photon energy shift in the P $2 \mathrm{p}$ spectra between the monodentate and bidentate adsorbed phosphonate groups. It has been shown that for phosphoric acid-terminated molecules that for each proton that is removed upon adsorption there is a shift of $\approx 1 \mathrm{eV}$ to lower binding energy. ${ }^{49}$ Therefore, the BE separation here between the two doublets would suggest a change in coordination of the phosphonate group from $\mathrm{P}(\mathrm{O})_{3}{ }^{2-}$ to $\mathrm{P}(\mathrm{O})_{2}(\mathrm{OH})^{-}$. Theoretical work has suggested that the bidentate adsorption would dominate, but the energy difference between mono- and bidentate adsorption is small. ${ }^{32,33}$ It seems, at room temperature at least, the surface sustains a mixed bonding geometry similar to catechol adsorption on rutile $\mathrm{TiO}_{2}(110)$. $^{50}$

It is not possible from these data to determine whether there is a switch to the monodentate mode as the coverage increases, i.e., the bidentate adsorbed molecule "picks up" a proton from a surface hydroxyl, or whether it is merely a statistical effect such that increasing the coverage reduces the number of bidentate states available. Future work would aim to determine whether at much higher coverage the bidentate or monodentate mode would dominate. With regard to the bidentate adsorbed PPA molecules, the data are unable to distinguish between bidentate bridging or bidentate chelating adsorption geometries. Theory, however, suggests that the bidentate bridging mode is more energetically favorable. ${ }^{34,48}$ An illustration representing the proposed bonding mechanism, with respect to the surface $\mathrm{Ti}$, is shown in Figure 5.

NEXAFS. In order to probe the unoccupied molecular states and bonding geometry of the adsorbed PPA, NEXAFS measurements were carried out on 0.15 and $0.85 \mathrm{ML}$ coverages of PPA on anatase $\mathrm{TiO}_{2}(101)$. The spectra were recorded with the surface component of the electric vector of the incident 


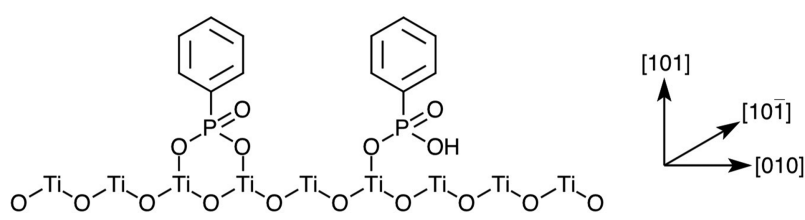

Figure 5. Illustration representing the proposed bonding mechanism of PPA on anatase $\mathrm{TiO}_{2}(101)$ as concluded from the XPS data.

light incident at $16^{\circ}$ from the $[10 \overline{1}]$ azimuth and $14^{\circ}$ to the [010] azimuth. The spectra are normalized by setting the edge jump from the background at 280 to $310 \mathrm{eV}$ photon energy to unity. The experimental spectrum recorded from the $0.85 \mathrm{ML}$ coverage with the synchrotron beam at normal incidence and the angle-integrated StoBe-calculated NEXAFS spectrum for an isolated PPA molecule are shown in Figure 6a. The calculated
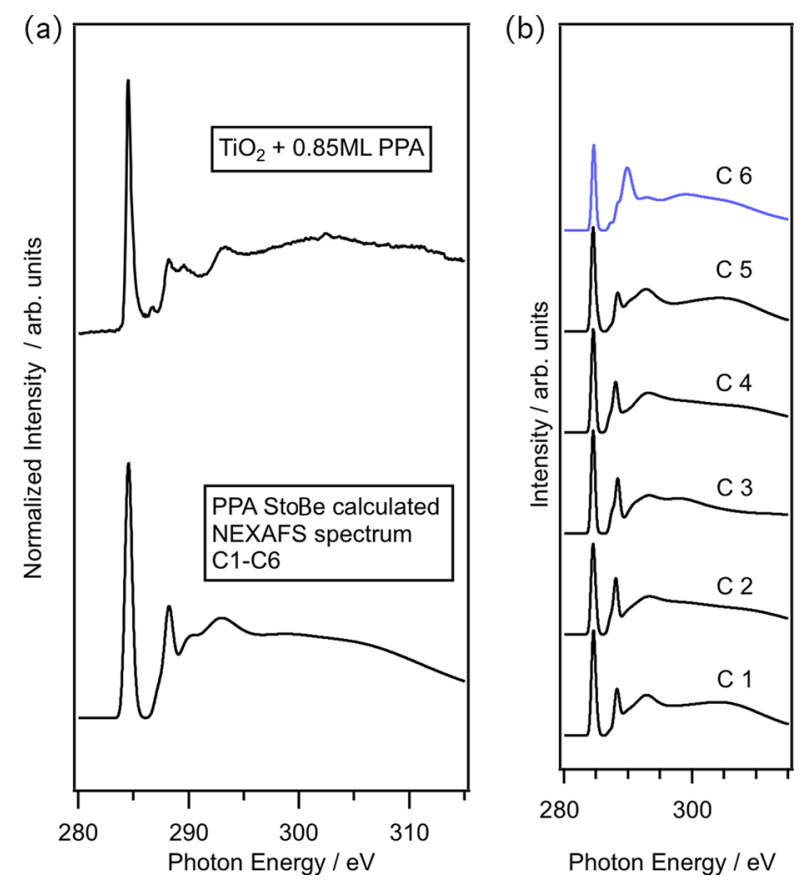

Figure 6. (a) NEXAFS spectra recorded from $0.85 \mathrm{ML}$ of PPA adsorbed on an anatase $\mathrm{TiO}_{2}(101)$ single crystal compared to the StoBe-calculated NEXAFS spectrum for the free PPA molecule. (b) The individual contributions from the carbon atoms are shown. These are labeled $\mathrm{C} 1-\mathrm{C} 6$ with respect to the carbon atoms shown in Figure 1 , with the phosphonated carbon highlighted in blue.

NEXAFS spectra at the $\mathrm{C}$ K-edge for the individual carbon atoms, as labeled in Figure 1, are shown in Figure 6b. Each spectrum is energy calibrated and convoluted with a Gaussian distribution to give a similar peak width to the experimental data. The calculated spectra, specific to each atom, can be used to determine the origin of the peaks seen in the experimental spectra. The calculated total NEXAFS spectrum in Figure 6a is aligned on the photon energy scale by aligning the main $\pi^{*}$ resonance to that of the experimental spectrum.

A sharp shape resonance can be seen in both the experimental and StoBe-calculated spectra at $284.5 \mathrm{eV}$, attributed to $\mathrm{C} 1 \mathrm{~s}_{\mathrm{C}-\mathrm{C}} \rightarrow$ ring $\pi_{1}^{*}$ transitions. Upon careful inspection, this peak is seen to be asymmetric to higher photon energies (see Supporting Information Figure S.3 for an expanded view of the spectra). This asymmetry is mainly due to the chemical shift induced in carbon atom C6 and is therefore attributed to $\mathrm{C} 1 \mathrm{~s}_{\mathrm{C}-\mathrm{P}} \rightarrow$ ring $\pi_{1}^{*}$ transitions. However, in addition to this the calculated spectra for $\mathrm{C} 1$ and $\mathrm{C} 5$ show some asymmetry. We assume this is related to excitation into $\pi_{2}^{*}$ states, i.e., $\mathrm{C} 1 \mathrm{~s}_{\mathrm{C}-\mathrm{C}} \rightarrow$ ring $\pi_{2}^{*}$ transitions. Note a small feature is present at $286.5 \mathrm{eV}$ in all experimental data but not present in the StoBe-calculated spectra, we therefore assume that this is substrate related. A clear peak can be seen at 288.2 $\mathrm{eV}$, which has been assigned to a mixture of Rydberg transitions and transitions to features of the $\mathrm{C}-\mathrm{H} \sigma^{*}$ bonds. ${ }^{51-53}$ The small bump at higher photon energy, at 289.7 and $290.0 \mathrm{eV}$ in the experimental and StoBe-calculated spectra, respectively, can only be seen in the C6 spectra and is therefore attributed to transitions $\mathrm{C} 1 \mathrm{~s}_{\mathrm{C}-\mathrm{P}} \rightarrow \sigma^{*}$ transitions. The reason for the difference in energy of the experimental and calculated spectra in this region is unclear. It is possible that the difference occurs as a result of the adsorption on the $\mathrm{TiO}_{2}$ surface, since the calculated spectrum is for the isolated molecule. However, it may also occur as a result of $\mathrm{C}$ contamination of the beamline optics leading to a loss of incident photon flux at these energies. This results in dip at around $290 \mathrm{eV}$, seen in all experimental spectra. Broader peaks at energies above $290 \mathrm{eV}$ have been assigned to $\mathrm{C} 1 \mathrm{~s}_{\mathrm{C}-\mathrm{C}} \rightarrow$ ring $\sigma^{*}$ transitions.

Figure 7 shows the angle-resolved carbon K-edge NEXAFS spectra of PPA adsorbed on anatase $\mathrm{TiO}_{2}(101)$ for incident radiation angles of $20^{\circ}-90^{\circ}$ to the surface, in increments of $10^{\circ}$. Fitting to a plot of peak intensity versus incidence angle using the equations of Stöhr, for a surface of 2-fold or higher symmetry, ${ }^{54}$ gives a tilt angle for the plane of the phenyl ring of $65 \pm 5^{\circ}$ relative to the surface and twisted roughly $57 \pm 8^{\circ}$ from the $[10 \overline{1}]$ azimuth. The tilt angle of $25^{\circ}$ from the surface normal is similar to that seen for other nonsubstituted aromatic molecules adsorbed in a bidentate fashion on this surface. ${ }^{12,41,55}$ Although the molecule is tilted relative to the macroscopic surface, the angle roughly correlates with the molecule in a geometry which is normal to the sawtooth structure of the anatase $\mathrm{TiO}_{2}$ surface as shown in Figure 8. Analysis of the XPS spectra shows that at higher coverages PPA shifts to a mixed bidentate/monodentate binding mode, but the NEXAFS data are unable to distinguish between the two binding modes. It is possible that both modes will lead to the molecule exhibiting similar tilt angles since previous DFT calculations have suggested that the tilt angle variation between coverages is small. ${ }^{52}$ However, if there are differences in the tilt angle, then the angles obtained from NEXAFS will be an average of the tilt and twist angles the two modes.

Summary. The adsorption of phenylphosphonic acid on the anatase $\mathrm{TiO}_{2}(101)$ surface, under ultrahigh-vacuum conditions, has been studied using photoelectron and NEXAFS spectroscopy. The data suggest that at low coverage the molecule adsorbs in a bidentate geometry following deprotonation of both phosphonate hydroxyl groups. As the coverage is increased, a mixed bidentate/monodentate binding mode develops. From the data presented here it is not possible to determine whether this mixed mode results from bidentate adsorbed molecules switching to monodentate or as the surface becomes more crowded that only monodentate adsorption can occur. Angle-resolved NEXAFS measurements suggest the molecule is oriented with the plane of the ring roughly $25^{\circ}$ relative to the surface normal, i.e., perpendicular to the sawtooth planes of the (101) surface. The upright geometry combined with the mixed monodentate/bidentate bridging adsorption mode suggests that molecules terminated with a phenylphosphonic acid group show potential for linking 

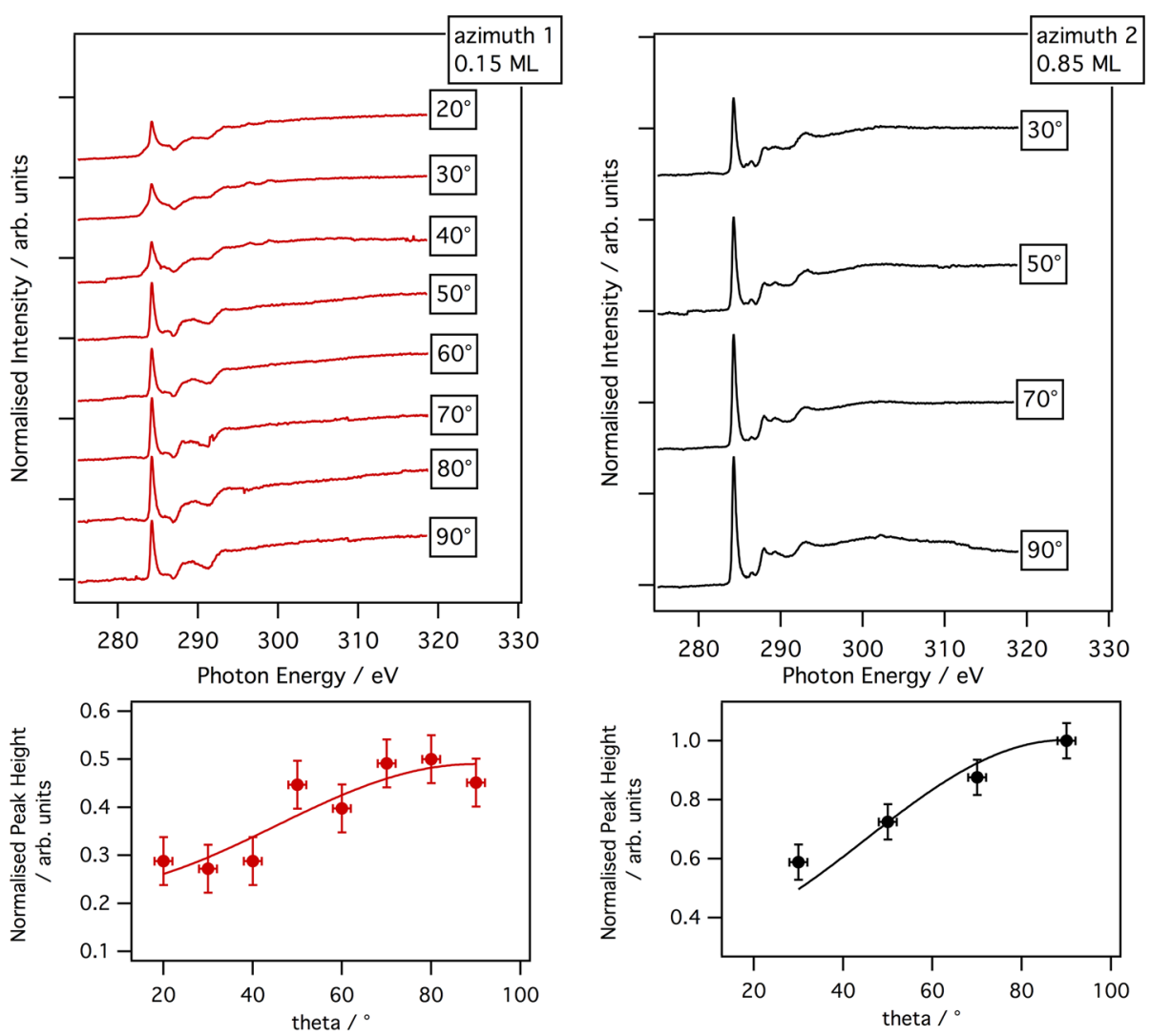

Figure 7. Top: carbon K-edge NEXAFS spectra of PPA adsorbed on the anatase $\mathrm{TiO}_{2}(101)$ surface. The spectra labeled azimuth 1 are recorded with the surface component of the electric vector of the incident light incident at $16^{\circ}$ from the [101] azimuth. The data in the plot labeled azimuth 2 are recorded with the E-vector $14^{\circ}$ to the [010] azimuth. Bottom: plot of the $\pi^{*}$ peak intensity plotted as a function of angle of photon incidence relative to the surface. The Stöhr equations have been fitted to the data points. ${ }^{54}$

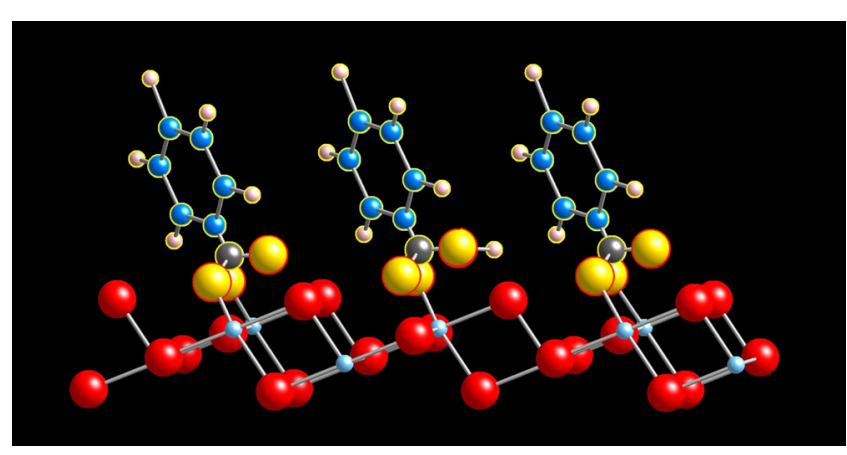

Figure 8. Schematic figure of the bonding modes of phenylphosphonic acid on the anatase $\mathrm{TiO}_{2}(101)$ surface. This figure depicts both the bidentate (left and right) and monodentate (middle) bonding modes. The oxygen atoms in the PPA molecule are colored gold in order to distinguish them from the substrate oxygen atoms, colored red.

quantum dots or biomolecules to titania surfaces. The experimental data show that although it has been suggested that phosphonic acids form a stronger bond than carboxylic acids, this increased stability does not involve a tridentate bonding mode, in agreement with theoretical predictions.

\section{ASSOCIATED CONTENT}

\section{S Supporting Information}

The Supporting Information is available free of charge on the ACS Publications website at DOI: 10.1021/acs.jpcc.5b11258.

Survey scan of a clean anatase $\mathrm{TiO}_{2}(101)$ surface (S.1); calculation showing how the coverage of PPA on anatase
$\mathrm{TiO}_{2}(101)$ was determined and the quantitative definition of a monolayer (S.2); expanded NEXAFS spectra highlighting the asymmetry of the main $\pi^{*}$ peak (S.3) (PDF)

\section{AUTHOR INFORMATION}

\section{Corresponding Author}

*E-mail andrew.g.thomas@manchester.ac.uk; Ph +44 161306 8764 (A.G.T.).

\section{Notes}

The authors declare no competing financial interest.

\section{ACKNOWLEDGMENTS}

M.W. acknowledges a Doctoral training award studentship from EPSRC and a University of Manchester President's Scholarship; M.J.J. holds a studentship funded by the EPSRC Doctoral Training Centre NowNano (grant EP/G03737X/1). M.T.M. is funded by BP ICAM. The authors thank the EPSRC UK for funding via travel grant EP/M026817/1 and MAXLab and the Swedish Research Council for the beamtime award.

\section{REFERENCES}

(1) O’Regan, B.; Grätzel, M. A low-cost, high-efficiency solar cell based on dye-sensitized colloidal $\mathrm{TiO}_{2}$ films. Nature 1991, 353, 737740.

(2) Ko, K. H.; Lee, Y. C.; Jung, Y. J. Enhanced efficiency of dyesensitized $\mathrm{TiO}_{2}$ solar cells (DSSC) by doping of metal ions. J. Colloid Interface Sci. 2005, 283, 482-487. 
(3) Zhang, Q.; Cao, G. Nanostructured photoelectrodes for dyesensitized solar cells. Nano Today 2011, 6, 91-109.

(4) Reddy, P. Y.; Giribabu, L.; Lyness, C.; Snaith, H. J.; Vijaykumar, C.; Chandrasekharam, M.; Lakshmikantam, M.; Yum, J.-H.; Kalyanasundaram, K.; Grätzel, M.; et al. Efficient sensitization of nanocrystalline $\mathrm{TiO}_{2}$ films by a near-IR-absorbing unsymmetrical zinc phthalocyanine. Angew. Chem., Int. Ed. 2007, 46, 373-376.

(5) Crossland, E. J. W.; Noel, N.; Sivaram, V.; Leijtens, T.; Alexander-Webber, J. A.; Snaith, H. J. Mesoporous $\mathrm{TiO}_{2}$ single crystals delivering enhanced mobility and optoelectronic device performance. Nature 2013, 495, 215-219.

(6) Fujishima, A.; Honda, K. Electrochemical photolysis of water at a semiconductor electrode. Nature 1972, 238, 37-38.

(7) Henderson, M. A. A surface science perspective on $\mathrm{TiO}_{2}$ photocatalysis. Surf. Sci. Rep. 2011, 66, 185-297.

(8) Murphy, M.; Walczak, M.; Hussain, H.; Acres, M.; Muryn, C.; Thomas, A.; Silikas, N.; Lindsay, R. An ex situ study of the adsorption of calcium phosphate from solution onto $\mathrm{TiO}_{2}(110)$ and $\mathrm{Al}_{2} \mathrm{O}_{3}(0001)$. Surf. Sci. 2015, DOI: 10.1016/j.susc.2015.08.040.

(9) Fei Yin, Z.; Wu, L.; Gui Yang, H.; Hua, S. Y. Recent progress in biomedical applications of titanium dioxide. Phys. Chem. Chem. Phys. 2013, 15, 4844-4858.

(10) Tsuchiya, H.; Macak, J. M.; Müller, L.; Kunze, J.; Müller, F.; Greil, P.; Virtanen, S.; Schmuki, P. Hydroxyapatite growth on anodic $\mathrm{TiO}_{2}$ nanotubes. J. Biomed. Mater. Res., Part A 2006, 77A, 534-541.

(11) $\mathrm{Yu}, \mathrm{J}$. C. Effects of F-doping on the photocatalytic activity and microstructures of nanocrystalline $\mathrm{TiO}_{2}$ powders. Chem. Mater. 2002, $14,3808-3816$.

(12) Thomas, A. G.; Jackman, M. J.; Wagstaffe, M.; Radtke, H.; Syres, K.; Adell, J.; Lévy, A.; Martsinovich, N. Adsorption studies of paminobenzoic acid on the anatase $\mathrm{TiO}_{2}(101)$ surface. Langmuir 2014, 30, 12306-12314.

(13) Hug, H.; Bader, M.; Mair, P.; Glatzel, T. Biophotovoltaics: natural pigments in dye-sensitized solar cells. Appl. Energy 2014, 115, 216-225.

(14) Mayor, L. C.; Ben Taylor, J.; Magnano, G.; Rienzo, A.; Satterley, C. J.; O'Shea, J. N.; Schnadt, J. Photoemission, resonant photoemission, and X-ray absorption of a $\mathrm{Ru}(\mathrm{II})$ complex adsorbed on rutile $\mathrm{TiO}_{2}(110)$ prepared by in situ electrospray deposition. J. Chem. Phys. 2008, 129, 114701.

(15) Britton, A. J.; Weston, M.; O'Shea, J. N. Charge transfer from an aromatic adsorbate to a semiconductor $\mathrm{TiO}_{2}$ surface probed on the femtosecond time scale with resonant inelastic X-ray scattering. Phys. Rev. Lett. 2012, 109, 017401.

(16) Katono, M.; Bessho, T.; Meng, S.; Humphry-Baker, R.; Rothenberger, G.; Zakeeruddin, S. M.; Kaxiras, E.; Grätzel, M. D- $\pi$ A dye system containing cyano-benzoic acid as anchoring group for dye-sensitized solar cells. Langmuir 2011, 27, 14248-14252.

(17) Margraf, J. T.; Ruland, A.; Sgobba, V.; Guldi, D. M.; Clark, T. Quantum-dot-sensitized solar cells: understanding linker molecules through theory and experiment. Langmuir 2013, 29, 2434-2438.

(18) Mora-Seró, I.; Giménez, S.; Moehl, T.; Fabregat-Santiago, F.; Lana-Villareal, T.; Gómez, R.; Bisquert, J. Factors determining the photovoltaic performance of a CdSe quantum dot sensitized solar cell: the role of the linker molecule and of the counter electrode. Nanotechnology 2008, 19, 424007.

(19) Schnadt, J.; Brühwiler, P. A.; Patthey, L.; O'Shea, J. N.; Södergren, S.; Odelius, M.; Ahuja, R.; Karis, O.; Bässler, M.; Persson, P.; et al. Experimental evidence for sub-3-fs charge transfer from an aromatic adsorbate to a semiconductor. Nature 2002, 418, 620-623.

(20) Hagfeldt, A.; Graetzel, M. Light-induced redox reactions in nanocrystalline systems. Chem. Rev. 1995, 95, 49-68.

(21) Zabri, H.; Gillaizeau, I.; Bignozzi, C. A.; Caramori, S.; Charlot, M.-F.; Cano-Boquera, J.; Odobel, F. Synthesis and comprehensive characterizations of new cis- $\operatorname{RuL}(2) \mathrm{X}(2)(\mathrm{X}=\mathrm{Cl}, \mathrm{CN}$, and NCS $)$ sensitizers for nanocrystalline $\mathrm{TiO}_{2}$ solar cell using bis-phosphonated bipyridine ligands (L). Inorg. Chem. 2003, 42, 6655-6666.

(22) Gillaizeau-Gauthier, I.; Odobel, F.; Alebbi, M.; Argazzi, R.; Costa, E.; Bignozzi, C. A.; Qu, P.; Meyer, G. J. Phosphonate-based bipyridine dyes for stable photovoltaic devices. Inorg. Chem. 2001, 40, 6073-6079.

(23) Zakeeruddin, S. M.; Nazeeruddin, M. K.; Pechy, P.; Rotzinger, F. P.; Humphry-Baker, R.; Kalyanasundaram, K.; Grätzel, M.; Shklover, V.; Haibach, T. Molecular engineering of photosensitizers for nanocrystalline solar cells: a synthesis and characterization of $\mathrm{Ru}$ dyes based on phosphonated terpyridines. Inorg. Chem. 1997, 36, 5937-5946.

(24) Ganbold, E. O.; Lee, Y.; Lee, K.; Kwon, O.; Joo, S. W. Interfacial behavior of benzoic acid and phenylphosphonic acid on nanocrystalline $\mathrm{TiO}_{2}$ surfaces. Chem. - Asian J. 2010, 5, 852-858.

(25) Gao, W.; Dickinson, L.; Grozinger, C.; Morin, F. G.; Reven, L. Self-assembled monolayers of alkylphosphonic acids on metal oxides. Langmuir 1996, 12, 6429-6435.

(26) Guerrero, G.; Mutin, P. H.; Vioux, A. Anchoring of phosphonate and phosphinate coupling molecules on titania Particles. Chem. Mater. 2001, 13, 4367-4373.

(27) Pawsey, S.; Yach, K.; Reven, L. Self-assembly of carboxyalkylphosphonic acids on metal oxide powders. Langmuir 2002, 18, 52055212.

(28) Lafont, U.; Simonin, L.; Gaberscek, M.; Kelder, E. Carbon coating via an alkyl phosphonic acid grafting route: Application on $\mathrm{TiO}_{2}$. J. Power Sources 2007, 174, 1104-1108.

(29) Paramonov, P. B.; Paniagua, S. A.; Hotchkiss, P. J.; Jones, S. C.; Armstrong, N. R.; Marder, S. R.; Brédas, J.-L. Theoretical characterization of the indium tin oxide surface and of its binding sites for adsorption of phosphonic acid monolayers. Chem. Mater. 2008, 20, $5131-5133$

(30) Brodard-Severac, F.; Guerrero, G.; Maquet, J.; Florian, P.; Gervais, C.; Mutin, P. H. High-field 17 O MAS NMR investigation of phosphonic acid monolayers on titania. Chem. Mater. 2008, 20, 51915196.

(31) Galoppini, E. Linkers for anchoring sensitizers to semiconductor nanoparticles. Coord. Chem. Rev. 2004, 248, 1283-1297.

(32) Luschtinetz, R.; Frenzel, J.; Milek, T.; Seifert, G. Adsorption of phosphonic acid at the $\mathrm{TiO}_{2}$ anatase (101) and rutile (110) surfaces. J. Phys. Chem. C 2009, 113, 5730-5740.

(33) Ambrosio, F.; Martsinovich, N.; Troisi, A. Effect of the anchoring group on electron injection: theoretical study of phosphonated dyes for dye-sensitized solar cells. J. Phys. Chem. C 2012, 116, 2622-2629.

(34) O'Rourke, C.; Bowler, D. R. DSSC anchoring groups: a surface dependent decision. J. Phys.: Condens. Matter 2014, 26, 195302.

(35) Patthey, L.; Rensmo, H.; Persson, P.; Westermark, K.; Vayssieres, L.; Stashans, A.; Petersson, Å.; Brühwiler, P. A.; Siegbahn, H.; Lunell, S.; et al. Adsorption of bi-isonicotinic acid on rutile $\mathrm{TiO}_{2}(110)$. J. Chem. Phys. 1999, 110, 5913-5918.

(36) Jackman, M. J.; Thomas, A. G.; Muryn, C. Photoelectron spectroscopy study of stoichiometric and reduced anatase $\mathrm{TiO}_{2}(101)$ surfaces: the effect of subsurface defects on water adsorption at nearambient pressures. J. Phys. Chem. C 2015, 119, 13682-13690.

(37) Choudhury, T.; Saied, S. O.; Sullivan, J. L.; Abbot, A. M. Reduction of oxides of iron, cobalt, titanium and niobium by lowenergy ion bombardment. J. Phys. D: Appl. Phys. 1989, 22, 1185-1195.

(38) Frisch, M. J.; Trucks, G. W.; Schlegel, H. B.; Scuseria, G. E.; Robb, M. A.; Cheeseman, J. R.; Montgomery, J. A.; Vreven, T.; Kudin, K. N.; Burant, J. C.; et al. Gaussian 03, Revision C.02; Gaussian, Inc.: Wallingford, CT, 2004.

(39) Hermann, K.; Pettersson, L. StoBe-deMon software. Stockholm - Berlin, version 2.2 of deMon, 2006.

(40) Bishop, H. E. The effects of photoelectron diffraction on quantitative X-ray photoelectron spectroscopy. Surf. Interface Anal. 1991, 17, 197-202.

(41) Syres, K. L.; Thomas, A. G.; Flavell, W. R.; Spencer, B. F.; Bondino, F.; Malvestuto, M.; Preobrajenski, A.; Grätzel, M. Adsorbateinduced modification of surface electronic structure: pyrocatechol adsorption on the anatase $\mathrm{TiO}_{2}(101)$ and rutile $\mathrm{TiO}_{2}$ (110) surfaces. J. Phys. Chem. C 2012, 116, 23515-23525. 
(42) Li, S.-C.; Wang, J.-g.; Jacobson, P.; Gong, X.-Q.; Selloni, A.; Diebold, U. Correlation between bonding geometry and band gap states at organic-inorganic interfaces: catechol on rutile $\mathrm{TiO}_{2}(110)$. J. Am. Chem. Soc. 2009, 131, 980-984.

(43) Li, S.-C.; Losovyj, Y.; Diebold, U. Adsorption-site-dependent electronic structure of catechol on the anatase $\mathrm{TiO}_{2}$ (101) surface. Langmuir 2011, 27, 8600-8604.

(44) Zorn, G.; Adadi, R.; Brener, R.; Yakovlev, V. A.; Gotman, I.; Gutmanas, E. Y.; Sukenik, C. N. Tailoring the surface of NiTi alloy using PIRAC nitriding followed by anodization and phosphonate monolayer deposition. Chem. Mater. 2008, 20, 5368-5374.

(45) Walle, L. E.; Borg, A.; Johansson, E. M. J.; Plogmaker, S.; Rensmo, H.; Uvdal, P.; Sandell, A. Mixed dissociative and molecular water adsorption on anatase $\mathrm{TiO}_{2}$ (101). J. Phys. Chem. C 2011, 115, 9545-9550.

(46) Tsud, N.; Yoshitake, M. Vacuum vapour deposition of phenylphosphonic acid on amorphous alumina. Surf. Sci. 2007, 601, 3060-3066.

(47) Adden, N.; Gamble, L. J.; Castner, D. G.; Hoffmann, A.; Gross, G.; Menzel, H. Phosphonic acid monolayers for binding of bioactive molecules to titanium surfaces. Langmuir 2006, 22, 8197-8204.

(48) Nilsing, M.; Lunell, S.; Persson, P.; Ojamäe, L. Phosphonic acid adsorption at the $\mathrm{TiO}_{2}$ anatase (101) surface investigated by periodic hybrid HF-DFT computations. Surf. Sci. 2005, 582, 49-60.

(49) Textor, M.; Ruiz, L.; Hofer, R.; Rossi, A.; Feldman, K.; Hähner, G.; Spencer, N. D. Structural chemistry of self-assembled monolayers of octadecylphosphoric acid on tantalum oxide surfaces. Langmuir 2000, 16, 3257-3271.

(50) Li, S.-C.; Chu, L.-N.; Gong, X.-Q.; Diebold, U. Hydrogen bonding controls the dynamics of catechol adsorbed on a $\mathrm{TiO}_{2}(110)$ surface. Science 2010, 328, 882-884.

(51) Hähner, G. Near edge X-ray absorption fine structure spectroscopy as a tool to probe electronic and structural properties of thin organic films and liquids. Chem. Soc. Rev. 2006, 35, 1244-1255. (52) Gliboff, M.; Sang, L.; Knesting, K. M.; Schalnat, M. C.; Mudalige, A.; Ratcliff, E. L.; Li, H.; Sigdel, A. K.; Giordano, A. J.; Berry, J. J.; et al. Orientation of phenylphosphonic acid self-assembled monolayers on a transparent conductive oxide: a combined NEXAFS, PM-IRRAS, and DFT study. Langmuir 2013, 29, 2166-2174.

(53) Harding, K.; Kalirai, S.; Hayes, R.; Ju, V.; Cooper, G.; Hitchcock, A.; Thompson, M. Inner-shell excitation spectroscopy of peroxides. Chem. Phys. 2015, 461, 117-124.

(54) Stöhr, J. NEXAFS Spectroscopy; Springer-Verlag: Berlin, 2003.

(55) Thomas, A.; Flavell, W.; Chatwin, C.; Rayner, S.; Tsoutsou, D.; Kumarasinghe, A.; Brete, D.; Johal, T.; Patel, S.; Purton, J. Adsorption of bi-isonicotinic acid on anatase $\mathrm{TiO}_{2}(101)$ and (001) studied by photoemission and NEXAFS spectroscopy. Surf. Sci. 2005, 592, 159168. 